How to cite: Urițescu, B., Grigoraș, G., Ionac, N. (2019) The Influence of Urban Morphology on the Urban Microclimate. 2019 "Air and Water - Components of the Environment" Conference Proceedings, Cluj-Napoca, Romania, p. 311-322, DOI: 10.24193/AWC2019_31.

\title{
THE INFLUENCE OF URBAN MORPHOLOGY ON THE URBAN MICROCLIMATE
}

\author{
Bogdan URIȚESCU ${ }^{1,3}$, Georgiana GRIGORAȘ ${ }^{2}$, Nicoleta IONAC \\ DOI: 10.24193/AWC2019_31
}

\begin{abstract}
In this paper, GIS techniques and satellite data are used in order to analyze the impact of the two types of urban design existing in the neighborhoods of Bucharest on the local microclimate. The two types of urban morphology considered are separated in time by a natural event, the earthquake from 1977, a phenomenon that has changed the evolution of urban planning of the city. The stages of the study are: i) geospatial analysis of urban morphology with emphasis on the construction features of each period; ii) spatial analysis of the land surface temperature in correlation with urban morphology, using Landsat satellite images; iii) microclimate simulation using ENVImet software to highlight the local thermal environment. The analysis of satellite data highlighted higher values of the land surface temperature in neighborhoods built after 1977 compared to ones built before that year. The simulation results highlight the differences of thermal environment between the two categories analyzed, lower values of air and surface temperatures for the neighborhoods built before 1977.
\end{abstract}

Keywords: urban microclimate; simulation; urban morphology; ENVI-met

\section{INTRODUCTION}

Worldwide, the migration of population from rural areas to urban areas has led to the expansion of urban areas. The development of cities leads to the transformation of green areas, agricultural land, wetlands or lakes into urban areas (Zhou and Chen, 2018). Also, rapid urbanization changes the constructive features of the city, increasing the built-up area and the density of buildings, changing the ratio between average building height and the width of the roads, favoring the appearance of street canyons and generating thermal differentials within the urban area (Dhar and Khirfan, 2017; Li et al., 2017; Liu et al., 2018; Sharma and Joshi, 2016; Cheval and Dumitrescu, 2017; Urițescu et al., 2017). By absorbing the radiation, storing heat in built surfaces, increased roughness and decreased evaporation, the rapid urbanization is considered to be the major factor causing the Urban Heat Island phenomenon (UHI). This phenomenon (UHI) is manifested by higher values of temperatures in the

${ }^{1}$ University of Bucharest, Faculty of Geography, Bvd. Nicolae Bălcescu no.1, 1st District, 010041, Bucharest, Romania E-mail: bogdan_uri@yahoo.com

${ }^{2}$ National Institute for Aerospace Research "Elie Carafoli" - INCAS, Bvd. Iuliu Maniu no. 220, 6th District, 061126, Bucharest, Romania

${ }^{3}$ National Institute for Research and Development in Environmental Protection, Bvd. Splaiul Independentei no.294,6th District, 060031, Bucharest, Romania 
metropolitan area compared to the surrounding rural areas due to human activities (Tran et al., 2017; dos Santos et al., 2017; Yao et al., 2017).

Due to the appearance of the heat island, in the summer, urban heating is increasingly difficult to bear, and residents increasingly use air conditioning. This addiction, in turn, considerably increases the amount of human anthropic heat released, forming a vicious circle. Therefore, well-planned cities can considerably improve the urban thermal environment and can diminish the phenomenon of the urban heat island (Lin et al., 2017; Grigoraș and Urițescu, 2018). In order to prevent the deterioration of the urban climate and the environment, cities should be carefully planned before they are fully developed and this planning must be based on quantitative guidance.

The purpose of this study is to highlight the thermal environment in urban areas characterized by two types of urban morphology developed as a result of implementation of different urban planning. These two approaches of urban planning are separated in time by the 1977 earthquake. The effects of the two types of urban development are highlighted: i) based on spatial analysis applied to LST derived from LANDSAT satellite data, ii) as well on the surface and air temperatures simulated using the urban microclimate model, ENVI-met V4 (ENVI-met, 2019).

\section{DATA AND METHODS}

\subsection{The analyzed neighborhoods}

To highlight the two types of urban morphology, the one before the earthquake of 1977 and the one after 1977, the buildings and the green spaces which surrounds them have been digitized, from different neighborhoods of Bucharest, using Google Earth satellite images from different periods of 2018 and the web portal of Green Cadaster of the Bucharest Municipality. The analyzed neighborhoods are shown in Figure 1. For a correct delimitation for the two periods it was used an military topographic map (1: 25000) made during the 1977-1978 period.

\subsection{LST retrieval}

The satellite image was chosen from the warmest period of 2018, being the only picture with clear sky conditions available. This image was taken at 11:56 local time (satellite time passage).

Landsat L8 OLI was used to calculate the LST for 27.08.2018 (Sannigrahi, 2018).

First, the digital numbers (DN) was converted to top of the atmospheric (TOA) radiance value;

$\mathrm{L}_{\lambda}=\mathrm{M}_{\mathrm{L}} * \mathrm{Q}_{\mathrm{cal}}+\nabla_{\mathrm{L}}$

where

$\mathrm{M}_{\mathrm{L}}$ is the radiance multiplicative scaling factor,

$\nabla_{\mathrm{L}}$ is the radiance additive scaling factor.

After that, the effective at satellite temperature $\left(\mathrm{T}_{\mathrm{b}}\right)$ was computed as follows:

$\mathrm{T}_{\mathrm{b}}=\mathrm{K}_{2 / /} /\left[\mathrm{ln}\left(\left(\mathrm{K}_{1} / \mathrm{L}_{\lambda}\right)+1\right)\right]$ 
where

$\mathrm{K}_{1}$ and $\mathrm{K}_{2}$ are the first and second calibration constant for thermal band. For Landsat $8, \mathrm{~K}_{1}$ and

$\mathrm{K}_{2}$ are 774.89 and 1321.08 for band 10 and 480.89 and 1201.14 for band 11 , respectively.

Finally, LST was retrieved after converting the at-satellite brightness temperature $(\mathrm{K})$ to surface temperature:

$\mathrm{T}_{\mathrm{s}}=\left[\mathrm{T}_{\mathrm{b}} /\left(1+\left(\lambda \mathrm{T}_{\mathrm{b}} / \rho\right) \ln \varepsilon\right)\right]-273.15$

where $\quad \mathrm{T}_{\mathrm{s}}$ is at surface temperature $\left({ }^{\circ} \mathrm{C}\right), \lambda$ is the wavelength of radiance (11.5), $\varepsilon$ is the spectral emissivity.

$\rho=\mathrm{h} \times(\mathrm{c} / \sigma)$

where

$\mathrm{h}=$ Planck's constant $\left(6.626 * 10^{-34} \mathrm{Js}\right)$,

$\mathrm{c}=$ velocity of light $\left(2.998 * 108 \mathrm{~m} / \mathrm{s}^{-1}\right)$,

$\sigma=$ Boltzmann constant $\left(1.38 * 10^{-23} \mathrm{~J} / \mathrm{K}\right)$.

$\varepsilon=0.02644 \mathrm{P}_{\mathrm{v}}+0.96356$

where $\quad \mathrm{P}_{\mathrm{v}}=$ fractional vegetation cover can be extracted as follows: $\mathrm{P}_{\mathrm{v}}=\left[\left(\mathrm{NDVI}-\mathrm{NDVI}_{\min }\right) /\left(\mathrm{NDVI}_{\max }-\mathrm{NDVI}_{\min }\right)\right]^{2}$

\subsection{ENVI-met simulation}

The ENVI-met model was used to simulate the urban microclimate in selected neighborhoods. ENVI-met is a three-dimensional microclimate model, based on the fundamental laws of fluid dynamics and thermodynamics, designed to simulate complex surface-vegetation-air interactions in the urban environment. Numerical simulations were made for the day of 28.08.2018, for which the Landsat satellite image was also chosen. Using data recorded at the Filaret meteorological station, which belongs to the National Meteorological Administration, the following meteorological parameters have been defined ENVI-met simulations: wind speed, wind direction and air temperature. Implicit values of ENVI-met were used for roughness length and specific humidity at the model top. The numerical stability of the model and the minimization of boundary effects, which may affect the output data, have been secured by placing more nesting grids around the main model areas. The main modeling domain was: $100(\mathrm{x}) * 100(\mathrm{y}) * 45(\mathrm{z})$, with the $2 \mathrm{~m}$ step for each direction. In the article are presented, for the main field, results only for the surface temperature and the air temperature at $2 \mathrm{~m}$ height, for the time when the satellite passed.

\section{RESULTS AND DISCUSSIONS}

Two types of urban morphology, the one before 1977 (with extended green spaces) and the one after 1977 (with bigger built-up surfaces and reduced green areas), have been highlighted in this study, conducting a geospatial analysis on Bucharest's six neighborhoods, located in three areas (east, south and north), each area containing a neighborhood built before 1977 and one after, in its vicinity. For a 
more accurate analysis, digitized neighborhoods do not contain areas that include parks, commercial complexes, schools or polyclinics.

The results of the analysis are presented in graphical form in Figure 1 and in quantitative form (surface of analyzed area, surface and percentage of constructions in the analyzed area; surface and percentage of green spaces in the studied area) in Table 1.
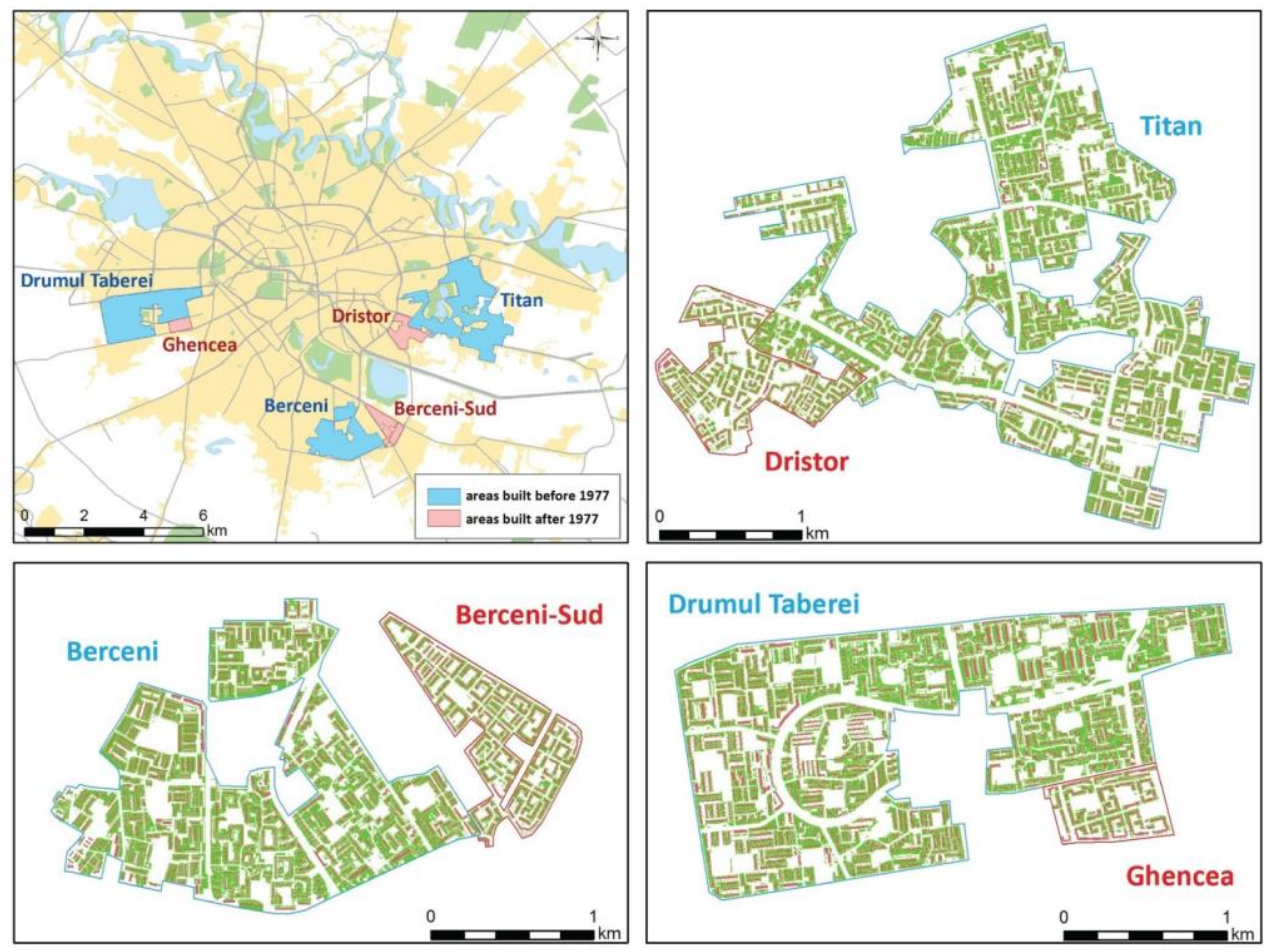

Fig. 1. Location of the analyzed neighborhoods in Bucharest and highlighting their urban morphology. Blue areas are neighborhoods built before 1977, red areas are neighborhoods built after 1977. In each neighborhood, the green areas represent green spaces and the brown areas are buildings.

Also, a spatial analysis of land surface temperature distribution derived from satellite data was carried out (shown in Figure 2). For each analyzed area there were extracted minimum values of LST $\left(\mathrm{T}_{\mathrm{s}} \mathrm{MIN}\right)$, maximum values ( $\left.\mathrm{T}_{\mathrm{s}} \mathrm{MAX}\right)$ and mean values $\left(\mathrm{T}_{\mathrm{s}}\right.$ MEAN) and the standard deviation was calculated (STD) for the LST mean values (presented in Table 1). The results presented in Table 1, shows that the urbanization plan applied after 1977, has the effect of reducing the green areas in favor of the built-up areas. Also, in correlation with the urban morphology types, it can be noticed that in the neighborhoods built after 1977, due to the increase of the surfaces occupied by buildings, the land surface temperature is higher by about one degree. 


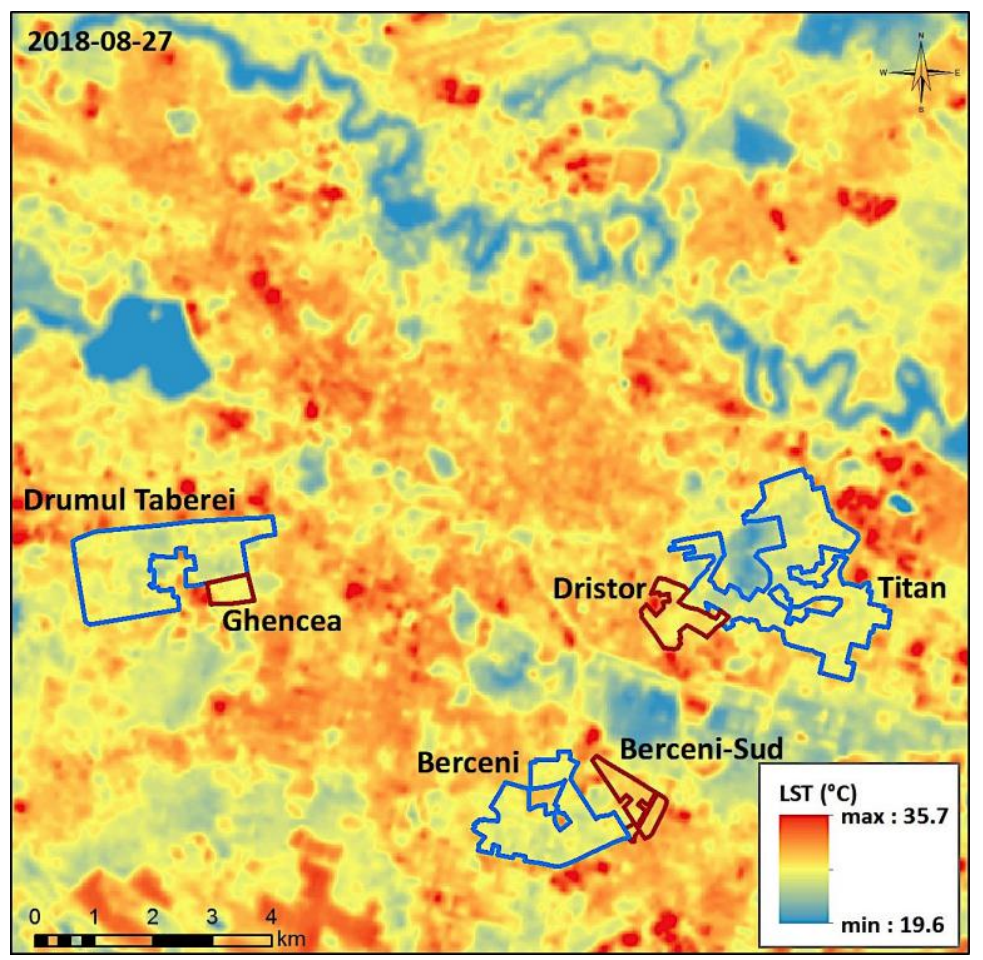

Fig. 2. Land surface temperatures derived from Landsat image (27.08.2018)

Because only LST values can be obtained from satellite images, to analyze the local thermal environment overall (both land surface temperature and air temperature, another important component of UHI and urban microclimate), using the ENVI-met model, comparative simulations were performed for neighboring areas from the analyzed neighborhoods, built before and after 1977.

Tabel 1. The spatial analysis results of the areas occupied by buildings and green spaces in the analyzed neighborhoods and the surface temperatures corresponding to the studied areas

\begin{tabular}{|l|c|c|c|c|c|c|c|c|c|c|}
\hline Neighborhood & $\begin{array}{c}\text { Construction } \\
\text { period }\end{array}$ & $\begin{array}{c}\text { Surface } \\
\text { area } \\
\left(\mathrm{km}^{2}\right)\end{array}$ & $\begin{array}{c}\text { Buildings } \\
\left(\mathrm{km}^{2}\right)\end{array}$ & $\begin{array}{c}\text { Buildings } \\
\text { from total } \\
\text { area }\end{array}$ & $\begin{array}{c}\text { Green } \\
\text { spaces } \\
\left(\mathrm{km}^{2}\right)\end{array}$ & $\begin{array}{c}\text { \% Green } \\
\text { spaces } \\
\text { from total } \\
\text { area }\end{array}$ & $\begin{array}{c}\mathrm{T}_{\mathrm{s}} \\
\mathrm{MIN} \\
(\mathrm{C})\end{array}$ & $\begin{array}{c}\mathrm{T}_{\mathrm{s}} \\
\mathrm{MAX} \\
(\mathrm{C})\end{array}$ & $\begin{array}{c}\mathrm{T}_{\mathrm{s}} \\
\text { MEAN } \\
(\mathrm{C})\end{array}$ & $\begin{array}{c}\text { STD } \\
(\mathrm{C})\end{array}$ \\
\hline $\begin{array}{l}\text { Drumul } \\
\text { Taberei }\end{array}$ & $1965-1977$ & 3.51 & 0.51 & 14.5 & 1.19 & 33.9 & 25.80 & 29.90 & 27.50 & 0.68 \\
\hline Titan & $1965-1977$ & 4.78 & 0.66 & 13.8 & 1.57 & 32.8 & 25 & 30 & 27.4 & 0.61 \\
\hline Berceni & $1965-1977$ & 2.48 & 0.36 & 14.5 & 0.9 & 36.3 & 26.2 & 30.5 & 27.7 & 0.61 \\
\hline Ghencea & $1978-1984$ & 0.3 & 0.06 & 20.0 & 0.05 & 16.7 & 26.6 & 30.9 & 28.2 & 0.64 \\
\hline Dristor & $1978-1984$ & 0.74 & 0.14 & 18.9 & 0.16 & 21.6 & 27.1 & 31.2 & 28.4 & 0.48 \\
\hline Berceni-Sud & $1978-1984$ & 0.62 & 0.14 & 22.6 & 0.15 & 24.2 & 27.9 & 29.9 & 28.8 & 0.31 \\
\hline
\end{tabular}

For each comparison, the areas built before and after 1977 had the same surface, the same orientation of the buildings, the same building materials (for buildings 
and streets) and same vegetation types. Areas have been compared from the neighborhoods: Berceni and Berceni-sud. Drumul Taberei and Ghencea, Titan and Dristor (represented in Figure 3).
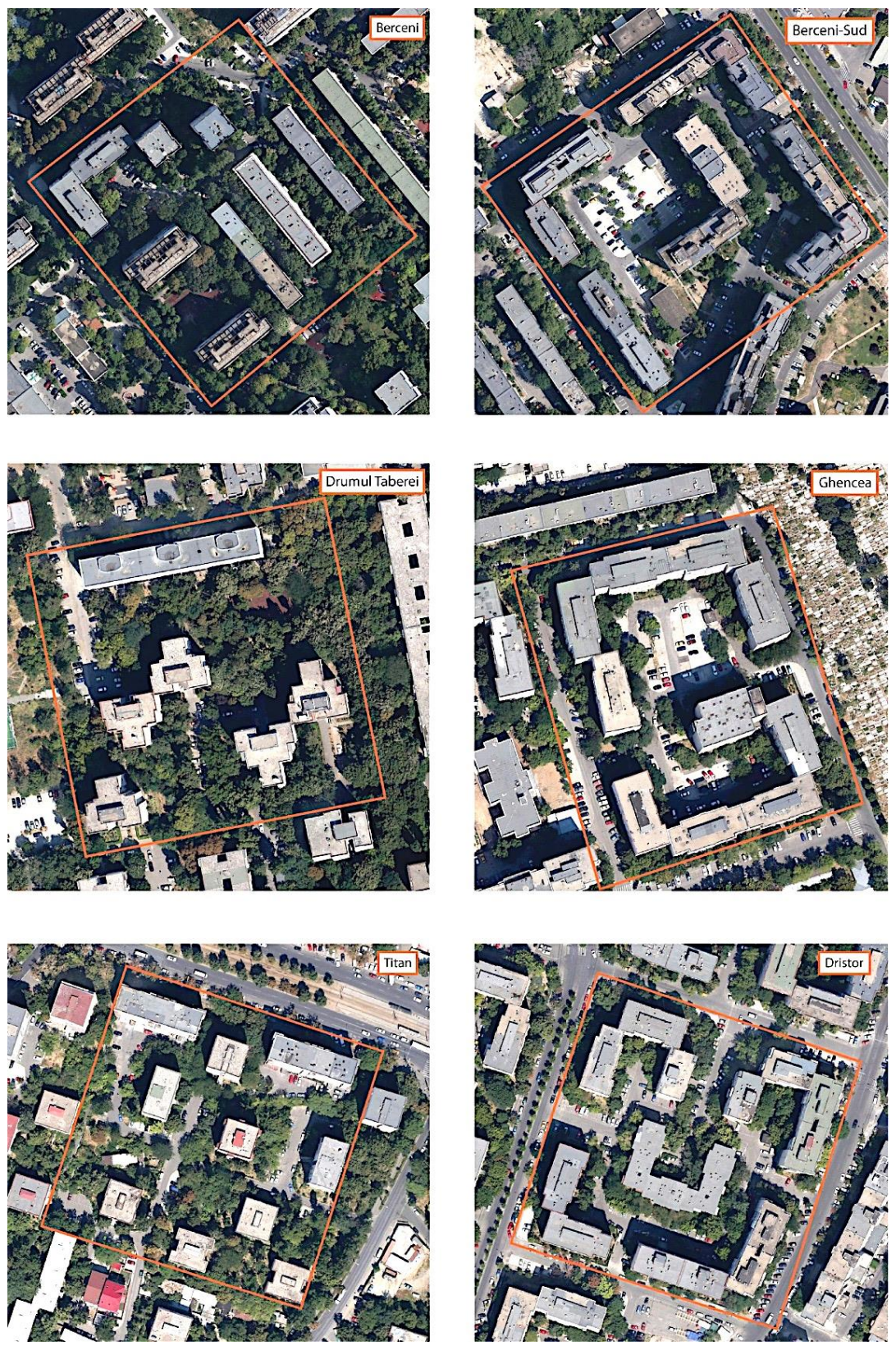

Fig. 3. Representation of areas for which urban microclimate simulations were conducted using the ENVI-met model (up - Berceni and Berceni-sud, middle - Drumul Taberei and Ghencea, down - Titan and Dristor) 
In figures 4-6, for each area, the land surface temperatures and air temperatures (at $2 \mathrm{~m}$ height) resulted from simulations are shown. These results are for the date and time when the Landsat- 8 satellite passed.
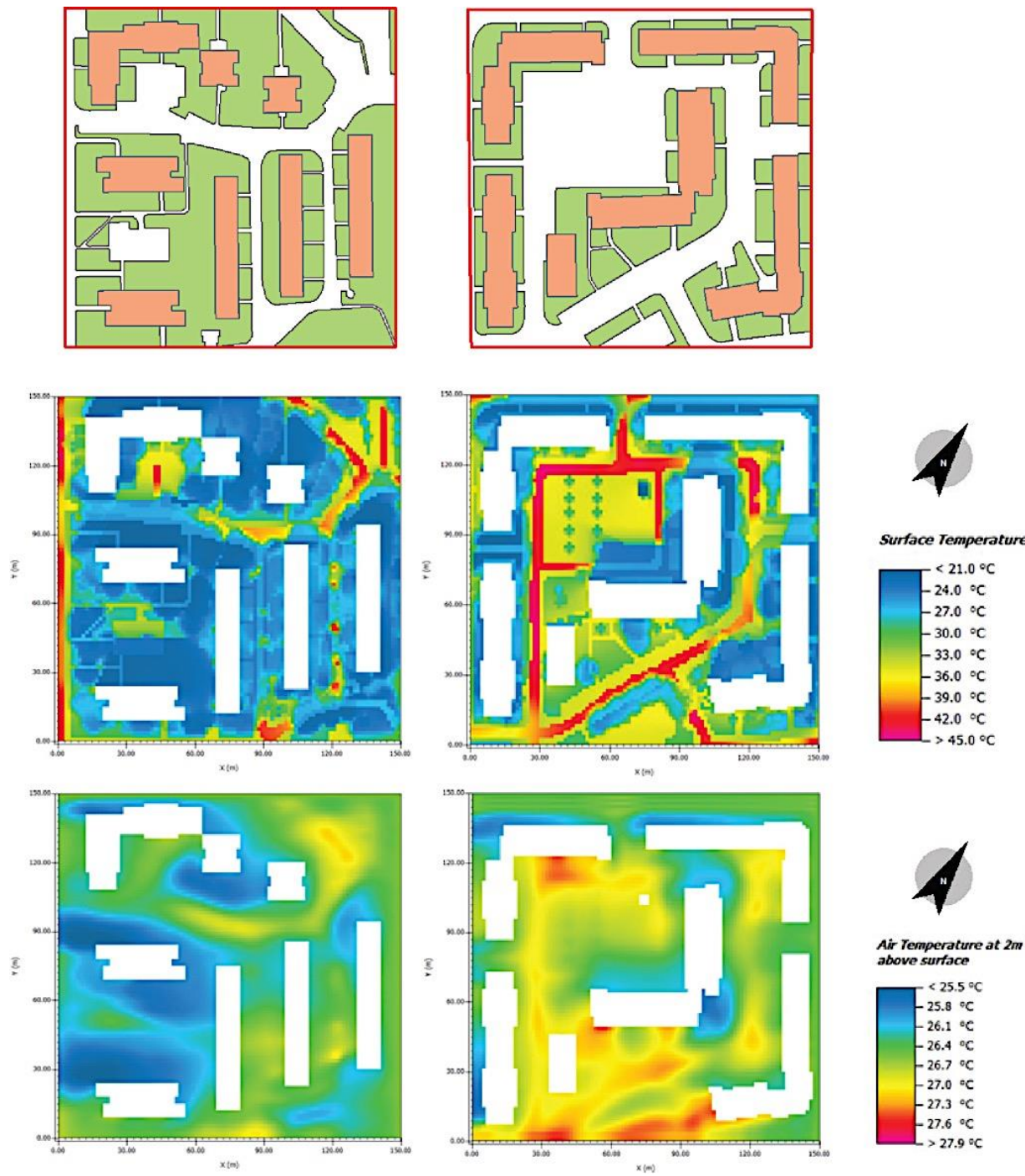

Fig. 4. Land surface temperature and air temperature for 12:00, Berceni (left) and Berceni-South (right), up - the digitized areas, middle - land surface temperature, down air temperatureat $2 m$ height

The results of the simulations show, for most scenes, a variation in the temperature between $21^{\circ} \mathrm{C}-45^{\circ} \mathrm{C}$ for LST and between $25,5^{\circ} \mathrm{C}-27,9^{\circ} \mathrm{C}$ for air temperature. The graphical representations of simulation results highlight low temperatures in larger surfaces for areas built before 1977, while areas built after 1977 show high temperatures on larger surfaces. 
From images representing modeled values of LST, there are differences between the analyzed categories due to several factors like shaded areas from trees or highrise buildings, concrete-covered surfaces, asphalt and green spaces, which varies depending on the scene.
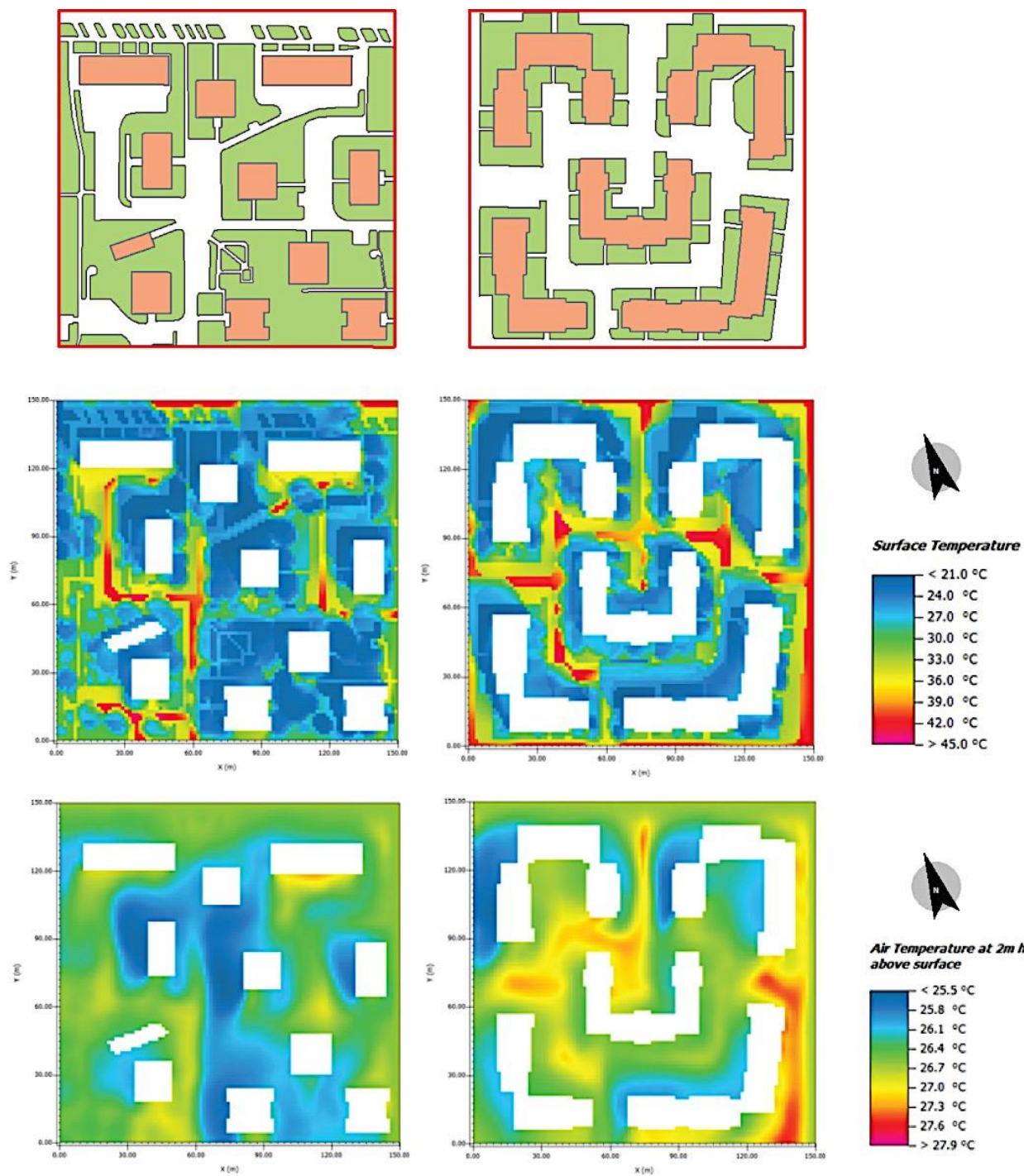

Air Temperature at $2 \mathrm{~m}$ height Air Temperature
above surface above surface

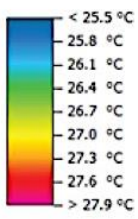

Fig. 5. Land surface temperature and air temperature for 12:00, Titan (left) and Dristor (right), up - the digitized areas, middle -land surface temperature, down - air temperature at $2 m$ height

Analyzing images for the first urban morphology category, it results that areas with low temperatures are generated by green areas, quite extpansive among buildings, which also include a large number of trees. Another feature is the low number of streets among the buildings which also contributes to lower LST values 
because vegetation has the property of reflecting solar radiation in a much larger quantity than asphalt and concrete). Analyzing images for the second urban morphology category, higher LST values can be notice due to urban planning change resulted by the earthquake of 1977, when the buildings have the surface extended, more streets were built and because the distance between buildings has remained the same, the areas occupied by the green spaces have been reduced.
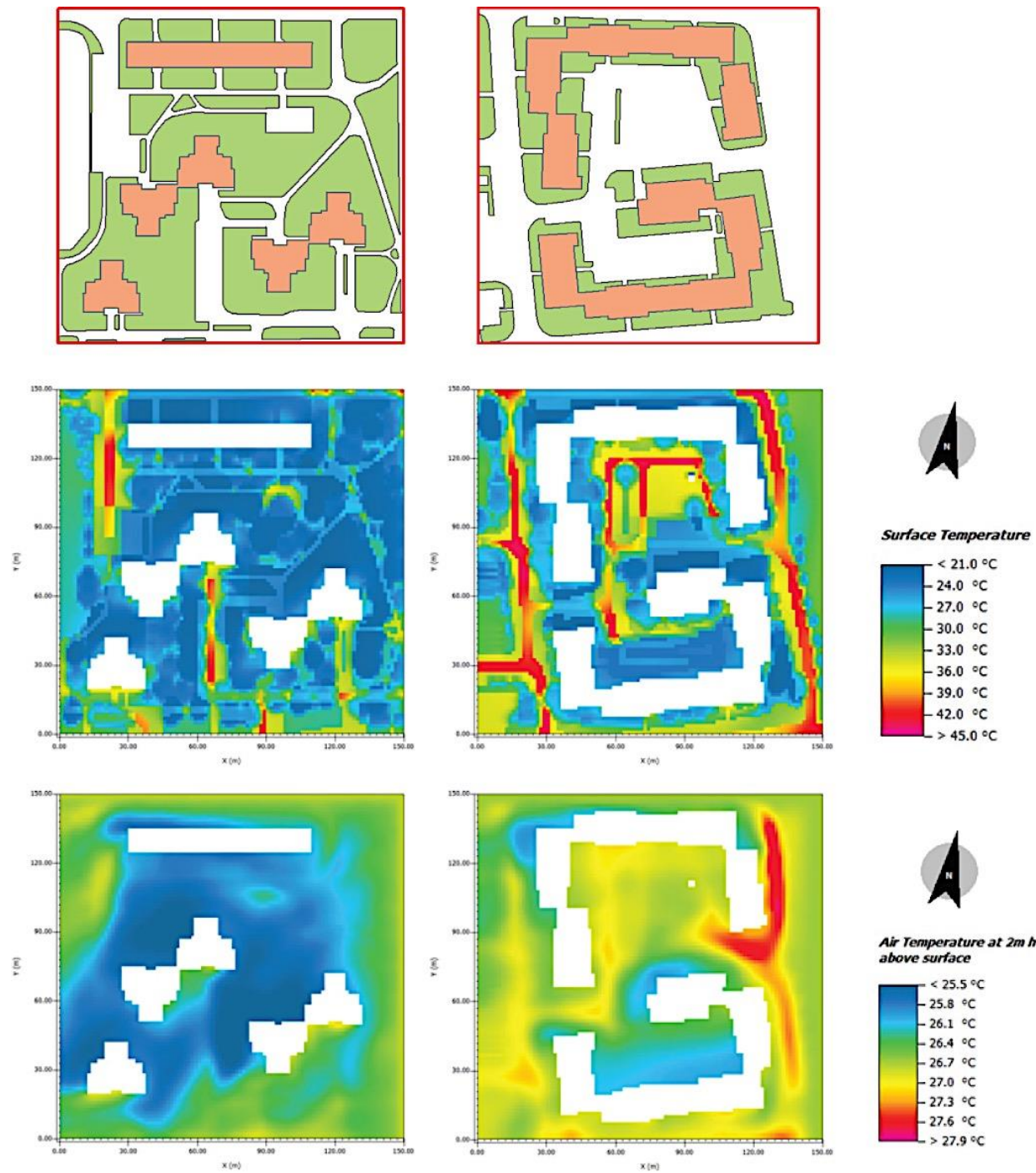

Fig. 6. Land surface temperature and air temperature for 12:00, Drumul Taberei (left) and Ghencea (right), up - the digitized areas, middle - land surface temperature, down air temperature at $2 m$ height

From the images representing the values of air temperature, a connection between the LST and the air temperature can be observed, but not overall, because 
the air temperature is also influenced by the vertical surfaces that can emit heat or generate shadow.

For the three images winch belong to the first urban morphology, there are small areas with high values of air temperatures corresponding to streets and car parks that were not in the shadow radius generated by other bodies, or which are located very close to buildings.

Low air temperatures are recorded on large surfaces, especially among buildings, the main reason being the presence of green spaces and the high number of trees.

For the other images that include areas built after 1977, high air temperatures can be noticed due to hot surfaces (streets, alleys and car parks) more numerous for these scenes, but also due to the reduced green spaces and a smaller number of large trees.

\section{CONCLUSION}

The article highlights two types of urban morphology resulting from the implementation of different urbanization plans, influenced and separated during the earthquake of 1977.

The effects of the two categories of urban morphology on urban microclimate are highlighted by geospatial analysis of land surface temperature distribution obtained from Landsat satellite data as well as simulating the land surface temperature and the air temperature, using the urban microclimate model, ENVImet.

The study revealed that the urban morphology developed before 1977 is characterized by a higher percentage of the areas occupied by green spaces, the ratio between the percentage of surfaces occupied by the green spaces and the percentage occupied by the built-up areas is 2.4 on average.

Urban morphology developed after 1977, prioritize the built-up areas, the ratio between the percentage of surfaces occupied by the green spaces and the percentage occupied by the built-up areas is on average equal with 1 .

Land surface temperature analysis determined from Landsat data highlights average surface temperatures in the neighborhoods built after 1977, on average higher by approximately one degree Celsius compared to average surface temperatures in neighborhoods built before 1977.

Also, the urban microclimate simulations with ENVI-met, highlight differences in the thermal environment for the two analyzed urban morphology categories. Low temperatures of both LST and air temperature for the neighborhoods built before 1977 were obtained, compared to those built after 1977 .

The results highlight the importance of green spaces in the urban and the need for better urban planning in the future that could reduce the effect of the urban heat island. 


\section{REFERENCES}

1. Cheval, S., Dumitrescu, A., (2017), Rapid daily and sub-daily temperature variations in an urban environment. Climate Research 73(3), 233-246. DOI: $10.3354 / \mathrm{cr} 01481$

2. Dhar, T.K., Khirfan, L., (2017), A multi-scale and multi-dimensional framework for enhancing the resilience of urban form to climate change. Urban Clim. 19, 7291. DOI: 10.1016/j.uclim.2016.12.004

3. dos Santos, A.R., de Oliveira, F.S., da Silva, A.G., Gleriani, J.M., Gonçalves,W., Moreira, G.L., Silva, F.G., Branco, E.R.F., Moura, M.M., da Silva, R.G., Juvanhol, R.S., de Souza, K.B., Ribeiro, C.A.A.S., de Queiroz, V.T., Costa, A.V., Lorenzon, A.S., Domingues, G.F., Marcatti, G.E., de Castro, N.L.M., Resende, R.T., Gonzales, D.E., Telles, L.A.A., Teixeira, T.R., dos Santos, G.M.A.D.A., Mota, P.H.S., (2017), Spatial and temporal distribution of urban heat islands. Sci. Total Environ. 605-606, 946-956. DOI: 10.1016/j.scitotenv.2017.05.275

4. ENVI-met, (2019). http://www.envi-met.info/doku.php

5. Grigoraş, G., Uriţescu, B., (2018), Spatial hotspot analysis of bucharest's uhi using MODIS data. Annals of Valahia University of Targoviste, Geographical series, vol.18(1). https://doi.org/10.2478/avutgs-2018-0002

6. Li, X., Zhou, Y., Asrar, G.R., Imhoff, M., Li, X., (2017), The surface urban heat island response to urban expansion: a panel analysis for the conterminous United States. Sci. Total Environ. 605-606, 426-435. DOI: 10.1016/j.scitotenv.2017.06.229

7. Lin, P., Lau, S.S.Y., Qin, H., Gou, Z., (2017), Effects of urban planning indicators on urban heat island: a case study of pocket parks in high-rise high-density environment. Landsc. Urban Plan. 168, 48-60. DOI: 10.1016/j.landurbplan.2017.09.024

8. Liu, X., Tian, G., Feng, J., Wang, J., Kong, L., (2018), Assessing summertime urban warming and the cooling efficacy of adaptation strategy in the ChengduChongqing metropolitan region of China. Sci. Total Environ. 610-611, 1092-1102. DOI: 10.1016/j.scitotenv.2017.08.082

9. Sannigrahi, S, Bhatt, S., Rahmat, S., Uniyal, B., Banerjee, S., Chakraborti, S., Jha, S., Lahiri, S., Santra, K., Bhatt, A., (2018), Analyzing the role of biophysical compositions in minimizing urban land surface temperature and urban heating. Urban Climate,24, 803-819, DOI:10.1016/j.uclim.2017.10.002

10. Sharma, R., Joshi, P.K., (2016), Mapping environmental impacts of rapid urbanization in the National Capital Region of India using remote sensing inputs. Urban Clim. 15, 70-82. DOI: 10.1016/j.uclim.2016.01.004

11. Tran, D.X., Pla, F., Latorre-Carmona, P., Myint, S.W., Caetano, M., Kieu, H.V., (2017), Characterizing the relationship between land use land cover change and land surface temperature. ISPRS J. Photogramm. Remote Sens. 124, 119-132. DOI: 10.1016/j.isprsjprs.2017.01.001

12. Urițescu, B., Ionac, N., Grigoraș, G., (2017), The influences of land use on the urban heat island in Bucharest. Iternational Conference Air and Water Components of the Environment; ISSN: 2067-743X; Cluj-Napoca; March, 17 19, 2017. DOI: 10.24193/AWC2017_32. 
13. Yao, R., Wang, L., Huang, X., Niu, Z., Liu, F., Wang, Q., (2017), Temporal trends of surface urban heat islands and associated determinants in major Chinese cities. Sci. Total Environ. 609, 742-754. DOI: 10.1016/j.scitotenv.2017.07.217

14. Zhou, X. and Chen, H., (2018), Impact of urbanization-related land use land cover changes and urban morphology changes on the urban heat island phenomenon, Science of the Total Environment 635, 1467-1476. DOI: 10.1016/j.scitotenv.2018.04.091 